\title{
Semiosis antropófaga como estrategia deconstructiva para una re-escritura* de la diferencia contracultural
}

*Nos referimos a la idea deconstructiva de escritura como marca, suplemento, injerto y diseminación, incorporándole el prefijo re para destacar la idea de que no es posible la marca escritural sin la repetición, la iteratividad, la marca del doble. Todos los ejemplos citados en el presente texto tienen esas características escriturales.

RodRigo Browne SARTORI

Universidad Austral de Chile (Valdivia) rodrigobrowne@uach.cl

Victor Silva Echeto Universidad de Playa Ancha (Chile) vsilva@upla.cl 


\section{Resumo}

Inspirado en las proyecciones devoradoras estimuladas por el Movimiento Antropófago que encabezaron Oswald de Andrade y Tarsila do Amaral a principios del siglo XX, el presente artículo pretende elucidar una estrategia deconstructiva que permita reescribir, contraculturalmente y desde el rescate de la diferencia, una semiótica antropófaga que desarticule los viejos y canonizados estereotipos construidos bajo la lógica eurooccidental y defienda espacios intermedios, desautorizaciones, silencios y secretismos. El ejemplo que acompaña permanentemente la propuesta teórica descansa en una crítica a los códigos semióticos que, desde la colonización, se han erigido en torno a los caníbales y a los antropófagos materiales.

\section{Palabras clave}

Semiótica - antropofagia - canibalismo - escritura - deconstrucción - contracultura.

\section{Abstract}

Inspired by the devouring implications stimulated by the Anthropophagous Movement led by Oswald de Andrade and Tarsila do Amaral at the beginning of the XX Century, the following article intends to elucidate a deconstructive strategy which allows to rewrite - in a countercultural way and starting from a recognition of the difference -, an anthropophagous semiotics which will dismantle the old and canonized stereotypes built under the Euro-Occidental logic, and will defend the intermediate spaces, the disauthorizations, silences, and secrecy. The example which permanently accompanies this theoretical proposal hinges on a criticism at the semiotic codes which, since colonization, have emerged around the cannibals and the material anthropophagous.

\section{Key Words}

semiotics, anthropophagi, cannibalism, writing, deconstruction, counterculture. 
"Casi me atrevería a decir que no entiendo la deconstrucción sin el escándalo, sin aquello que (la) derriba y (la) hace caer a cada paso interrumpiendo su marcha, su continua cadencia"

Paco Vidarte.

" $Y$ en efecto: la 'oblique offering', que no era menos mía que suya, tenía un dejo irónico, sarcásticamente eucarístico (ningún vegetariano -y yo conozco al menos dos entre los convidados- nunca podrá romper con la sublimidad del canibalismo místico): ¿el 'este es mi cuerpo, se os entrega, guardadlo como recuerdo de mí no es acaso el don más oblicuo? ¿Acaso no lo he comentado a lo largo de años en Glas o en seminarios recientes sobre el 'comer al otro' y la 'retórica del canibalismo'? Razón de más para no responder. Esta no es una Cena, y la irónica amistad que nos reúne consiste en saberlo, al mismo tiempo que lanzamos una mirada estrábica con un 'squinty eye' hacia ese canibalismo enlutado".

Jacques Derrida.

\section{Primera inscripción de-velada: la des(autor)ización antropófaga.}

\footnotetext{
A principios del siglo XX, Oswald de Andrade hace público su "Manifiesto Antropófago". El objetivo de esta provocación artístico-filosófica es reivindicar la tradición antropófaga que proviene y despierta de los olvidados aborígenes que habitaban en la selva Amazónica. El último día de la felicidad fue el 11 de octubre de 1492 sentencian las fauces de los devoradores y hambrientos intelectuales paulistas.
} 
La idea, sin duda, es coquetear en y con los límites de las conciencias occidentales para, con ello, superar las peculiares nociones de las vanguardias europeas, consumirlas, devorarlas y defecarlas con un fuerte carácter mestizo latinoamericanista. Es la resistencia tupi, el triunfo devorador de los Tupinambas: "Nunca fuimos catequizados. Lo que hicimos fue Carnaval. El indio vestido como senador del Imperio" (De Andrade, 1928).

La antropofagia como lucha y resistencia frente a una sociedad occidental y occidentalizada que invita -de y en acuerdo con sus propios intereses- al consumo simbólico de una sola y victoriosa verdad. "Contra la Memoria fuente de la costumbre. La experiencia personal renovada" (De Andrade, 1928). La misión del vanguardista colectivo de los antropófagos brasileños es familiarizar la ajenidad y la marginalidad que construye el discurso de autoridad y aceptar los nomadismos y las migraciones contraculturales. "Las migraciones. La fuga de los estados tediosos. Contra las esclerosis urbanas. Contra los Conservatorios y el tedio especulativo" (De Andrade, 1928).

La verdad antropófaga no existe y para su existencia es necesaria la multiplicación y la carnavalización de los sentidos que se alejan de UNA VERDAD. Los sentidos y sus paradojas superan a la verdad única y definida, desequilibrándola, en virtud de un contrapensamiento que se deja llevar y permite la libre navegación por los canales de las diferencias.

Las voces de la intolerancia, las guerras, las ajenidades son síntomas del cansancio de las modernidades y sus consecuencias. El desgaste de occidente y sus secuaces se hace patente en el rescate antropófago. Es la crisis de las ciencias humanas y -como lo sugiere Foucault (1966)- la muerte del hombre. La propia des(autor)ización del autor occidental. En síntesis, es también la muerte del autor (Barthes, 1968; Foucault, 1969).

Por ejemplo, Borges no es el autor de su obra, sólo es quien habilita a un narrador que estimula las múltiples lecturas que se pueden desprender de un escrito: es la panacea antropófaga de la lecturaescritural y el quiebre de los límites entre autor y lector, entre devorado y devorador: "contra la verdad de los pueblos misioneros..." (De 
Andrade, 1928). Los narradores de Borges anulan la propia figura del Autor-Borges, le desautorizan y le hacen parte del silencio (Block de Behar, 1984). El silencio es el reto al que la escritura se enfrenta siempre. "Y, por tanto, el límite que la cerca, de ahí que, de alguna de las maneras posibles, se haga presente en las obras literarias desde su comienzo, que no podría ser sino él mismo, pues está ahí como condición misma de la palabra" (Blesa, 1998: 13). ${ }^{1}$ Por tanto, el silencio no es callar, sino, por el contrario, el discurso que tiene como condición la señal de que la palabra ha sido suprimida, el indicio que marca las huellas en las inscripciones de lo efímero. Una de las principales características del silencio es su indecidibilidad, es decir, aquello que no se dice, que no puede decirse sino solo balbucearse.

Escuchar las voces y escrituras de los silencios que desarticulan la condición del dios, que superan "La escritura del Dios" y que dan vida a muchas lecturas del Quijote -tal como lo hace Pierre Menard, uno de los tantos autores/otros del clásico de Cervantes. Es que las obras de Cervantes y de Menard son prácticamente idénticas pero, la del segundo de éstos es casi infinitamente más rica: "(Más ambiguo, dirán sus detractores; pero la ambiguiedad es una riqueza)" (Borges, 1979: 45). Como se plantearía, desde una lectura deconstructiva, y lo demuestra Pierre Menard, el lugar de la literatura es el lugar del secreto. "Sobre ese secreto se puede rodar, enredar, merodear y dar vueltas, pero el secreto permanecerá secreto" (Cragnolini, 2008: 9). Sobre el secreto se puede hablar pero, también, es la imposibilidad de referirse a una totalidad cerrada y representativa: "siempre se puede hablar sobre él, pero esto no basta para romperlo. Se puede hablar de él hasta el infinito, contar historias sobre él", pero el secreto permanecerá mudo (Derrida, 2008). El lugar del secreto "es, entonces, el lugar del resto que es nada, nada más que resto" (Cragnolini, 2008: 9 y Derrida 2008). En sentido benjaminiano es el espacio de las ruinas (Benjamin,

1. Sobre lo mismo, Blesa sostiene que es un "tópico de la escritura y, más en particular, de alguna de sus páginas, entre las que es forzado aludir a la mística, en donde se plantea una auténtica batalla con la incapacidad de la palabra para trasladar la experiencia absolutamente insólita" (Blesa, 1998: 13-14). 
1979), el imposible espacio de la representación. “(...) la literatura es para Derrida-siguiendo en esto a Blanchot-el lugar por excelencia del secreto". La expresión repetida (plus de secret, plus de secret) "patentiza la paradoja de la experiencia del secreto: no hay secreto como ocultamiento que puede ser desvelado -no hay ningún secreto, y por eso siempre hay más secreto. Estamos expuestos a ese secreto: ese secreto nos llama, ese secreto nos dice 'Ven"' (Cragnolini, 2008: 10). Al fin de cuentas, si todo es secreto y, por tanto, no hay más secretos que quieren ser develados aunque sepan de esa imposibilidad: ¿qué importa quién está hablando? Esta autorización a decirlo todo erige al autor, paradójicamente, en autor no responsable ante nadie, ni siquiera ante sí mismo, por ejemplo, de cuanto dicen las personas o personajes de sus obras y, en consecuencia, de lo que se supone él mismo ha escrito. "Y esas 'voces' atraen o convocan, inclusive en las literaturas sin persona y sin personaje. Esta autorización de decirlo todo (que corre pareja, sin embargo, con la democracia como hiper-responsabilización aparente del 'sujeto') reconoce un derecho a la no-respuesta absoluta, allí, donde no sería cuestión de responder, de poder o deber responder" (Derrida, 2008: 20-ss.). Esa no-respuesta es más originaria y más secreta, porque, en el fondo, es más heterogénea al origen y al secreto que las modalidades del poder y del deber. En definitiva, "allí estaría la pasión. No hay pasión sin secreto, este secreto, pero no hay secreto sin esta pasión. En lugar del secreto: allí, donde sin embargo, todo queda dicho y donde el resto no es nada -nada más que resto, ni siquiera literatura (Derrida, 2008). En Pierre Menard, pero, también, en las creaciones antropófagas (Macunaíma es un excelente ejemplo al respecto) no hay más que secretos y repeticiones, firmas e iteratividades, singularidades y suplementos, pastiche y diferencias: "por oposición a una relación de identidad o igualdad, que presupone intercambiabilidad mutua entre los términos (como en una ecuación matemática, donde el signo de igualdad significa precisamente tal posibilidad de sustitución), una repetición es el re-torno de algo que no puede ser reemplazado" (Avelar, 2000: 196). Aunque aparentemente es un oxímoron, la expresión deleuzeana repetición diferencial (Deleuze, 1992), "a menudo usada para definir la estructura

Significação $29 \cdot 148$ 
del pastiche sería de hecho redundante", porque la única posibilidad de la repetición es retornar desde la diferencia: "no quería escribir otro Quijote sino El Quijote" (Borges, 1979: 47). Es decir, una repetición sólo puede "tener lugar dentro de la diferencia: la repetición lleva consigo, necesariamente, el imperativo de la autodiferenciación". Avelar cita, también, el caso de Pierre Menard: "En el ejemplo ya clásico, Pierre Menard, al repetir el texto de Cervantes letra por letra, fuerza a Cervantes a diferenciarse de sí mismo, interrumpe la identidad de la firma de Cervantes consigo misma" (Avelar, 2000: 197). Como plantea Gilles Deleuze (1992) la repetición más exacta, la de la letra por letra (como en el poema), tiene su correlato en la diferencia. Nos encontramos frente a un pastiche, y, esta figura ( $l a$ del pastiche) no es una parodia como, tampoco, una repetición no es una identidad. "El emblema de la fisura entre la parodia y el pastiche la ofrece de nuevo Pierre Menard" (Avelar, 2000: 197) al no resignarse a la fácil empresa de componer otro Quijote sino al escribir (re-escribir) El Quijote. Nuevamente el secreto: “allí no hay tiempo ni lugar" sino "hay secreto". Se calla, no para conservar una palabra reservada o retirada, sino porque permanece extraño a la palabra, sin siquiera que se pueda decir -sintagma relevante- "el secreto, es lo que es, en la palabra, extraño a la palabra" (Derrida, 2008: 20-ss.). No responde a la palabra, no dice "Yo, el secreto", no corresponde, no responde: ni de él ni a nadie, ni ante algo o alguien. No-respuesta absoluta a la cual no se le podría siquiera pedir cuentas o dar a cuenta, pactar descargas, excusas o "descuentos", estratagemas siempre para arrastrarlo a un proceso filosófico, ético, político, jurídico, etc. El secreto no da lugar a ningún proceso. Ni siquiera es un "efecto de secreto" (Derrida, 2008: 20-ss.). Macunaíma, como ya se precisó, se mantiene en secreto...

\section{Segunda inscripción de-velada: Colón el libre hermeneuta}

El 12 de octubre de 1492 del calendario colonizador se llevó a cabo el primer encuentro entre miembros de la cultura euroccidental 
y representantes del "nuevo mundo". Estos últimos, fueron catalogados, curiosamente y a pesar de ser los invadidos, como "Otros", a partir de la mismidad predominante de los recién llegados:2 "Es sabido que la frontera de la persona como fenómeno de la semiótica histórico-cultural depende del modo de codificación" (Lotman, 1984: 24-25).

Colón ante la necesidad de hacer realidad su sueño y dar con los supuestos dominios del Gran Kan (Señor de los señores) o emperador de China -personaje del cual tenía referencias por los relatos de viaje de Marco Polo- comienza a realizar las más diversas interpretaciones de la lengua de los nativos -por esto Todorov (1982) bautizó al Almirante como un "hermeneuta". Un ejemplo elocuente ante lo dicho fue cuando el navegante denominó a los antropófagos como caníbales, tras una libre e interesada adaptación del término nativo cariba y al comprender "(...) de la lengua de los nativos lo que quiere entender, desechando categóricamente toda diversidad semántica..." (Reding Blase, 1996: 36).

Cuando arriba a la pequeña isla de los Guanahani en el archipiélago de las Lucayas, Colón, “obcecado por las pasiones", interpreta a los isleños y entiende que en dirección al sur del territorio se encontraban las grandes islas denominadas Colba (actualmente Cuba) y Bohío (Haití) y supuso -ante su deseo incontrolado por llegar a las tierras del Gran Kan- que el tan anhelado Cipango estaba a la vuelta de la esquina. En relación a estas deducciones del navegante, Todorov (1982) es categórico al asegurar que Colón escucha cariba y lo asocia con la gente del Kan, sin invertir mayor tiempo en el intento de comprensión del otro.

Poco después de referirse a lo complejo que es señalar con exactitud el inicio de la práctica caníbal, y con respecto al caso específico de América del Sur, W. Arens no escatima comentarios acerca de que el primer tema relativamente concreto de estudio

2. El conquistador sabía, de ante mano, lo que tenía que "descubrir" para que la "empresa" fuese redonda. La experiencia que se rescatará en este texto es la del propio Cristóbal Colón.

Significação $29 \cdot 150$ 
antropófago es el de los cariba, “(...) de cuyo nombre derivó, a través del español de la época, la palabra caníbal” (Arens, 1979: 47). Para Roberto Fernández Retamar (1995: 27) el nombre caribe y su degeneración a caníbal quedaron estampadas entre los europeos, "(...) sobre todo de manera infamante". A modo de ejemplo para la proyección en el "nuevo mundo" de los imaginarios que circulaban y circularon por la vieja Europa, este intelectual cubano expone la visión que sobre Caliban ${ }^{3}$ (re)presenta el propio Shakespeare en su obra La Tempestad (1613): Caliban "es anagrama forjado por Shakespeare a partir de 'caníbal' -expresión que, en el sentido de antropófago, ya había empleado en otras obras, como La tercera parte del Rey Enrique VI y Otelo- y este término, a su vez, proviene de 'caribe' (...) en Shakespeare (...)" Caliban/caníbal "es un esclavo salvaje y deforme para quien son pocas las injurias. Sucede que Shakespeare, implacable realista, asume aquí al diseñar caliban la otra opción del naciente mundo burgués" (Fernández Retamar, 1995: 27 y 30).

Marvin Harris (1997) aporta un interesante ejemplo en torno a las particulares y codificadas interpretaciones de las lenguas nativas precolombinas por parte de los conquistadores y su futura adaptación al castellano de la época. Para ello, este antropólogo se refiere a la palabra "barbacoa": "Proviene de la palabra carib barbricot. Los carib -de ahí la palabra "caníbal"- utilizaban la barbricot, una parilla hecha con ramas verdes, para preparar sus festines caníbales" (Harris, 1997: 160).

3. "Si al nacer fue llamado por su prodigioso inventor Cáliban, con acento en la primera a, ello se debe a que es anagrama del inglés cannibal. En francés, debido a similar razón, de la palabra cannibale, ya presente en Montaigne, se derivó Calibán, acentuada desde luego en la segunda a (...) Y en español, por contagio francés, aceptamos y propagamos (yo también lo hice, de modo copioso) 'Calibán' (...) Sin embargo, en nuestra lengua, después de todo la madre del cordero, Colón, de la palabra caribe, hizo caniba, y luego caníbal, cuyo anagrama lógico es Caliban, palabra llana que es la que empleo desde hace tiempo, a partir de una conferencia que ofrecí en Santiago de Cuba (...) Me gustaria que se aceptara esta sana rectificación, a sabiendas de lo difícil que es modificar arraigados hábitos lingüísticos mal avenidos con la lógica. Por mi parte, me parece bien paradójico que un texto que se quiere anticolonialista empiece por no serlo en el título mismo" (Fernández Retamar, 1999: 203-204). 
En definitiva, la semiosfera del colonizador no respetó la porosa frontera ${ }^{4}$ que permitía traducir abiertamente los mensajes externos y se dejó llevar por su lenguaje interno monologizador que, finalmente, dificultó el contacto entre los abstractos espacios semióticos de la semiosfera colonizada y colonizadora. Es así de sencillo como se institucionaliza en Europa la oscura figura de la bestia inhumana que se come a sus pares, siendo la única alternativa para eliminar estas acciones homogeneizar hacia la lógica occidental, es decir, occidentalizar "oriente".

Es la imposibilidad deconstructiva de la traducción que abre la posibilidad de la ruptura, del ritmo, de la cadencia, de los residuos (estos sí de lo traducido) como excremento: "el entrometerse de la ruina, de la ceniza, del resto, del desvío postal, de la promesa susceptible de traición, de lo intraducible, de la errancia, de lo indeconstructible quizás: no hay deconstrucción sin algo que se (le) entromete siempre y (le) impide la marcha, (la) obstaculiza, al modo de la más singular resistencia en deconstrucción" (Vidarte, 2008: 103). En términos de Derrida: "Caída prematura, lapsus, prolapsus, expresión, excremento, neonato suplantado, deformado y desviado, desde entonces, loco de deseo por renacer" (Derrida en Vidarte, 2008: 102).

\section{Tercera inscripción de-velada: "Somos gratamente los otros..."}

Estudios fundamentales en relación al canibalismo y la antropofagia son los que propone, en el siglo XVI y poco antes que Shakespeare escribiera sobre Calibán (Caliban), el noble francés Michel de Montaigne. Considerado como unos de los pioneros en el

4. Para Lotman, la frontera -como parte fundamental de la semiosfera- necesita de un entorno exterior "no organizado" que se construye en caso de ausencia de éste. "La cultura crea no sólo su propia organización interna, sino también su propio tipo de desorganización externa" (Lotman, 1984: 29). 
análisis de los actos antropófagos, este ex-concejal de Bordeaux irrumpe con unas ideas que fueron vitales para poner en tela de juicio la teoría homogeneizadora imperante. En su publicación "Des cannibales" del libro Essais (1604), el autor, en virtud de la creación de imágenes provenientes tanto de lo escritural como, posteriormente, de las artes plásticas -las construidas por los expedicionarios en América y las generadas por su directa influencia en el imaginario de los europeos- opina que es esencial redactar sólo sobre aquello que cada uno conoce y maneja con cierto conocimiento de causa.

Colón no sólo dio pie a la construcción del caníbal americano sino que, por otro lado, estimó que para el indio caníbal el comer carne humana era parte, por su truculencia y sabrosura sensacionalista, de un ritual digno de animalidad. Colón sentó bases transcendentales para colocar a occidente como centro dominador y hegemónico del mundo. Por la misma causa, Iain Chambers detecta este acto como un punto de partida para arribar a lo que, en la actualidad, son nuestras sociedades, “(...) cuando se empezó a imponer la visión occidental” (Chambers, 1998: 29). La eurocéntrica palabra descubrimiento fue, más bien, un encuentro de dos mundos que se ignoraban y donde uno se impuso frente al otro, al menos fuerte. Hombrecillos de menor importancia, desvestidos, inocentes y mansos que viven en la Edad de Oro, "(...) o execrables sodomitas antropófagos que deben vivir bajo tutela perpetua de Occidente, el Otro cultural, el hombre americano, finalmente está ausente porque se le describe bajo la perspectiva occidental..." (Reding Blase, 1992: 17).

Por lo visto, occidente, además de ser una excelente, exitosa y creativa máquina productora de imágenes se va transformando, al mismo tiempo, en el peor y el más avasallador aparato destructor. En este marco, zarpó Colón en busca de las "nuevas tierras", siendo su único y gran objetivo la expansión del imperio español y el desarrollo del capitalismo europeo. Reding Blase, denuncia que todo conquistador fue un encubridor ( $y$ no un descubridor) ya que encubrió una realidad que, siendo ajena a la suya, podría haber enriquecido su propio universo.

En el siglo XVI, Europa se considera el centro del universo, la única realidad posible, condicionando su futuro modelo imperialista. 
Bajo estas egocéntricas circunstancias, el Otro no existe, queda al margen y en la periferia. Por lo tanto, el centro sólo se dedica a conquistar y a vencer. La etapa de la "nueva América" comienza con una evolutiva disminución de la población indígena debido a las guerras, las epidemias y el hambre. En palabras de Eduardo Subirats: "El concepto de 'teología de la colonización' comprende desde su raíz constitutiva este proceso de aniquilación de las culturas no cristianas a una escala global" (Subirats, 2000: 89).

Completamente en contra de la teoría asimiladora e imperialista, Montaigne precisa que cada uno llama barbarie lo que está fuera de su alcance y defiende a los antropófagos aduciendo que no son más bárbaros que los colonizadores, quienes, en nombre de la religión, cometen actos mucho más despiadados.

El ensayo de Montaigne sobre el canibalismo es importante para entender que todo el etnocidio realizado por los europeos en América es un acto de "engullimiento" simbólico (ya que no comen literalmente) de una cultura, de una sociedad que, por el sólo capricho temporal de ser el centro de operaciones del mundo, logra destruir, apoderarse y aniquilar al extraño.

El Otro que se encuentra aislado, fuera de los márgenes establecidos y que, al ser colonizado, debe someterse a las normas y códigos de un dominador cuyo objetivo es, nada más y nada menos, que el de beneficiar la "voracidad" desmedida europea y colonizadora por medio de su explotación y abuso.

En su afán por devorarse toda cultura ajena, los colonizadores caen en una gran regresión primera (o primitiva desde la mirada occidental) que es denunciada por la vanguardia antropófaga de Oswald de Andrade y su colectivo engullidor. El europeo de la época se contradice a sí mismo en sus creencias trascendentales y sufre una suerte de involución a periodos prehistóricos ya que comienza, metafóricamente, a devorarse tribus desconocidas que son tildadas de no humanas, considerándose como los únicos hombres del universo.

No hay que desconocer que las teorías clásicas de la antropología dicen, en una de sus líneas de investigación, que un homínido se come a otro porque éste asegura que el otro no es hombre y se convence que no están comiendo seres iguales a ellos, sino 
inferiores, aunque sean vecinos y, en épocas anteriores, familiares cercanos. Entonces: ¿cómo pueden definirse los actos antropófagos de los cristianos? Es más ¿los cristianos no ejercían, previamente, una suerte de canibalismo simbólico o teofagia ${ }^{5}$ al comer la ostia como parte del cuerpo de Cristo?, sin olvidar, por supuesto, que Jesús también fue un hombre. "Kamper alinhava os pressupostos dogmáticos que dao origem às grandes descobertas. Para ele, o cristianismo abandonou seu horizonte a renunciar à diferença entre $o$ sagrado e o profano..." (Pelegrini, 2001: 3), habilitando y ayudando, con esto, a instalar la (auto)canibalización del mundo moderno.

Así es como posteriormente, el "complejo de culpa del europeo" o "la ética culpable del colonizador" los llevó a "descubrir" que su descubrimiento les permitió comerse simbólicamente a esos Otros como a sí mismos, dejando huellas imborrables de aquel engullimiento y haciendo que el crimen (el acto de "engullimiento") sea (im)perfecto.

Como precisa Jean Baudrillard, al referirse a la eliminación del Otro bajo todas sus formas, sin considerar las diferencias de raza y lengua: al tratar de eliminarlos para hacer relucir nuestra positividad total, estamos a un paso de eliminarnos nosotros mismos. Mismos que fueron víctimas de un acto de "autoengullimiento", de autoantropofagia simbólica, donde "(...) el asesino y la víctima son una misma persona..." (Gans en Baudrillard, 1995: 10) que "al destruir en el adversario la inhumanidad del contra-hombre" (Reding Blase, 168) no puede sino más que destruir la humanidad del hombre

5. "Dietmar Kamper, professor de sociologia e antropologia desde 1979, na Universidade Livre de Berlim, define o tema de fundo desta Reforma, que moldava as reflexoes da época. 'Tudo girava em torno da presença de Cristo na Santa Ceia', explica. Era uma leitura para entender o corpo de Cristo como corpo e outra para ocultá-lo, como signo. O catoliscimo e o protestantismo disputavam a visao da Santa Ceia como Comunhao ou Comunicaçao. A antropofagia e a teofagia começavam a fundar os códigos de uma Europa dispota a canibalizar o mundo em troca da comprovaçao de suas certezas. Staden testemunhou este conflito quando esteve como alimento-prisioneiro dos Tupinambás e os convenceu a nao transformá-lo em um banquete para os Deuses ou em um banquete" (Pelegrini, 2001: 2-3). 
y realizar en sí su inhumanidad. El narrador borgeano -al escribir desde el sacerdote indígena Tzinacán, encarcelado por los españolesbusca "La escritura del Dios", pero sumergido en la misma nocturnidad teñida por el euroccidentalismo predominante: "Ese hombre ha sido él y ahora no le importa. Qué le importa la suerte de aquel otro, qué le importa la nación de aquel otro, si él, ahora es nadie. Por eso no pronuncio la fórmula, por eso dejo que me olviden los días, acostado en la oscuridad" (Borges, 1949: 140-141).

\section{Cuarto inscripción de-velada: semiosis antropófaga contracultural}

La antropofagia paulista del '28, se ubica en un contexto de obras de ruptura (como la escritura borgeana) que deconstruyen el canon de la representación occidentalizadora de cierta modernidad, que instaló la comodidad representativa e intentó eliminar todos los residuos que se le escapaban a la mediación del signo, del lenguaje y, en definitiva, de la metafísica de la presencia. Pero esas marcas residuales aparecen por entre las grietas, se re-escriben y multiplican las paradojas del sentido-sinsentido. Performativamente aparecen desde las añadiduras del suplemento y desestabilizan el sentido de dirección única.

Esas tácticas y estrategias fueron las que impulsaron como prácticas subversivas de resistencias los antropófagos, cuestionando la identidad y las herramientas territorializadoras que interpretan y representan al Otro desde la mismidad.

Para vitalizar este ejercicio, es inminente deconstruir las enquistadas normas de la antropofagia material. La idea es batallar "contra la realidad social, vestida y opresora, catastrada por Freud la realidad sin complejos, sin locura, sin prostituciones y sin las prisiones del matriarcado de Pindorama" (De Andrade, 1928). ${ }^{6}$ Los

6. Oswald de Andrade explica que es necesario crear un nuevo espacio: el Matriarcado de Pindorama, el matriarcado de las palmeras, nombre de la tierra del Brasil en nheengutú, la lengua general de los habitantes de esa zona. 
antropófagos brasileños no escuchan las monógamas disciplinas, sino que gozan de sus nómadas indisciplinas, en busca de un intercambio promiscuo y desestabilizador. Es la radicalización y posterior ruptura del disciplinamiento foucaultiano y la entrada en vigor de la ilimitación de la semiosis. Semiosis antropófaga que concibe contrapensamientos superadores de las sorderas ideológicas (Peñuela, 2007) que despiertan el apetito en el amplio y frenético ámbito de la semiótica, como un dispositivo re-escritural de las verdades nómadas y no sedentarias; rizomáticas y no arbóreas ni monotemáticas.

\section{Bibliografia}

ANDRADE, Oswald de (1928). "Manifiesto antropófago" en HISTAL enero 2004. http://www.histal.umontreal.ca/espanol/documentos/ manifiestoantropofago.htm.

ARENS, W. (1979). El mito del canibalismo. Antropología y antropofagia. México, Siglo

XXI, 1981.

AVELAR, Idelber (2000). Alegorías de la derrota. La ficción postdictatorial y el trabajo del duelo. Santiago, Cuarto Propio.

BAUDRILLARD, Jean (1995). El crimen perfecto. Barcelona, Anagrama, 1996.

BARTHES, R. (1968). "La muerte del autor" en El susurro del lenguaje. Más allá de

las palabras y la escritura. Barcelona: Paidós, 1987.

BENJAMIN, Walter (1979). "Tesis sobre la filosofía de la historia" en Discursos interrumpidos. Madrid, Cátedra.

BLESA, Túa (1998). Logofagias. Zaragoza, Tropelías.

BLOCK DE BEHAR, L. (1984). Una retórica del silencio. Funciones del lector y procedimientos de lalectura literaria. México, Siglo XXI, 1994.

BORGES, J. L. (1949). "La escritura del Dios" en El Aleph. Madrid, Alianza, 2001.

(1979). Obras completas en colaboración. Buenos Aires, Emecé. 
CHAMBERS, I. (1998). "Cielos comunes, horizontes divididos. Entrevista a Iain Chambers", entrevista de Adell Joan-Elies en Quimera, $\mathrm{n}^{\circ}$ 174, Barcelona.

CRAGNOLINI, Mónica (2008). "Prólogo. Por amor a Derrida o por qué el amor es un cierto, extraño performativo" en Por amor a Derrida. Buenos Aires, La Cabra.

DERRIDA, Jacques (2008). Pasiones ("La ofrenda oblicua"), traducción de Jorge Panesi, material de la cátedra: Teoría y análisis literario "C", Facultad de Filosofía y Letras, Universidad de Buenos Aires. Edición digital de Derrida en castellano. Consultado el 8 de agosto de 2008 .

DELEUZE, Gilles (1989). Lógica del sentido. Barcelona, Paidós.

(1992). Diferencia y repetición. Madrid, Ediciones del Júcar.

ECO, U. (1990). Semiótica y filosofía del lenguaje. Barcelona, Lumen, 1995.

FERNÁNDEZ RETAMAR, R. (1995). Calibán Contra la Leyenda Negra. Lleida, Edicions de la Universitat de Lleida.

(1999). "Caliban ante la antropofagia" en Anthropophagy today?, Antropofagia hoje?, ¿Antropofagia hoy?, Antropofagia oggi?, Stanford, Nuevo Texto Crítico 23/24, Department of Spanish and Portuguese, enero-diciembre.

FOUCAULT, M. (1966). Las palabras y las cosas. México, Siglo XXI, 1996.

(1969). "Qué es un autor" en Henciclopedia, http://www. henciclopedia.org.uy/autores/Foucault/Autor.html. Montevideo, 2000.

HARRIS, M. (1977). Canibales y reyes. Los orígenes de las culturas. Barcelona, Argos, 1978.

LOTMAN, I. (1996). "Acerca de la semiosfera" en La semiosfera I. Madrid, Cátedra y Universidad de Valencia.

PEÑUELA, E. (2007). "Interdisciplinariedad, polisemia y dialogismo" en BROWNE, R., ONETTO, B. y VALENZUELA, Víctor Hugo (2007). Diálogos culturales. Interdisciplinas para la comunicación. Valdivia-Sao Paulo, Annablume.

PELEGRINI, M. (2001). “Antropofagia e teofagia”. GREBH, Revista del Centro Interdisciplinar de Semiótica da Cultura e da Mídia (CISC), Pontificia Universidad Católica de Sao Paulo, www.cisc.org.br/biblioteca/index.html, 
REDING BLASE, S. (1992). El buen salvaje y el canibal. México, U.A.M.

RODRIGO ALSINA, M. (2000). "Apuntes sobre una semiótica intercultural" en Actas del IX Congreso de la Asociación Española de Semiótica, Valencia.

SILVA ECHETO, V. y BROWNE, R. (2004). Escrituras híbridas y rizomáticas. Pasajes intersticiales, pensamiento del entre, comunicación y cultura. Sevilla, Arcibel.

(2007). Antropofagias. Las indisciplinas de la comunicación. Madrid, Biblioteca Nueva.

SUBIRATS, E. (2000). "Antropofagia contra globalización o el Paraíso en América Latina” En Quimera, n 193-194, Barcelona.]

TODOROV, T. (1982). La conquista de América. El problema del Otro. México, Siglo XXI, 1998.

VIDARTE, P. (2008). "De una cierta cadencia en deconstrucción" en Por amor a Derrida. Buenos Aires, La Cebra. 